\title{
O TEMPO SOCIAL E A VISÃO DIALÉTICA DA RELAÇÃO HOMEM-MEIO AMBIENTE COMO FUNDAMENTOS PARA A COMPREENSÃO DO DANO MORAL AMBIENTAL*
}

\author{
Luiza Landerdahl Christmann** \\ Luiz Ernani Bonesso de Araújo***
}

\begin{abstract}
RESUMO: No contexto do problema ambiental atual, destaca-se a Teoria da Reparação Integral dos danos causados ao meio ambiente, a qual preconiza a proteção ambiental na esfera patrimonial (elementos físicos da natureza) e moral (valores da coletividade e sadia qualidade de vida). A Lei 7347/85, alterada pela Lei 8844/94, trouxe a possibilidade de danos a direitos difusos e coletivos, tanto patrimoniais como extrapatrimoniais. Inobstante a positivação, há autores que rejeitam tal hipótese, defendendo que somente o ser humano, individualmente, pode sofrer dano moral. Por meio de uma visão dialética a respeito da relação homem-meio ambiente e da consideração do tempo social como construtor da identidade dos povos, com base na obra de François Ost, formulou-se uma base filosófica que possibilite a compreensão da moral ambiental em nível coletivo e, assim, o dano extrapatrimonial ambiental.
\end{abstract}

PALAVRAS-CHAVE: Dano ambiental. Dano moral. François Ost. Reparação integral.

ABSTRACT: In the context of the actual environmental problem, it detaches the Integral Reparation Theory of the damage caused to the environment, which advocate the environmental protection in patrimonial sphere (phisical elements of nature) and moral (community values and healthy quality of life). The Law 7347/85, modified by Law 8844/94, brought the possibility of damage to diffuse and collective rights, patrimonially and morally. Although the positive law, there are authors that reject this hypothesis, arguing that only human being, individually, can suffer moral damage. Through a dialectic vision regarding the men-environment relation and the consideration of the social time as people identity's constructer, based on François Ost's works, it was formulated a philosophical basis that makes possible the comprehension of environment moral in collective aspect and, therefore, the environment moral damage.

KEY-WORDS: Environment damage. Moral damage. François Ost. Integral reparation

*Este artigo constitui um recorte do projeto de pesquisa "O dano moral ambiental no ordenamento jurídico brasileiro", correspondente ao período de março/2007 a agosto/2007.

**Acadêmica do Curso de Direito da UFSM. Bolsista PIBIC/CNPq. Email: lululc_icq@ yahoo.com.br

***Professor do Curso de Direito da UFSM. Mestre e doutor em Direito pela Universidade Federal de Santa Catarina. 


\section{INTRODUÇÃO}

A temática que envolve a proteção ao meio ambiente hoje transcende à órbita dos Estados para ganhar espaço nas discussões internacionais. Nesse contexto, a Constituição Federal, em seu artigo 225, enuncia o direito de todos ao meio ambiente ecologicamente equilibrado, essencial à sadia qualidade de vida. Nessa busca, a preocupação com a reparação dos danos oriundos de desastres ambientais adquire relevância, pois atingem o meio no seu equilíbrio, interferindo na qualidade de vida do homem.

Nessa esteira, como tema freqüente no debate acadêmico e jurisprudencial, apresenta-se a Teoria da Reparação Integral, que preconiza a obrigação de restabelecimento da situação tanto na esfera patrimonial (elementos físicos da natureza) quanto moral (valores da coletividade e sadia qualidade de vida). Assim se defende porque a "sadia qualidade de vida" é conceito multidimensional, englobando o meio ambiente natural, artificial, cultural e do trabalho.

A responsabilidade geral pelos danos ambientais é prevista na Lei 6938/81, que determina a obrigação de indenizar ou reparar os danos causados ao meio e a terceiros, independentemente de culpa. Posteriormente, a Lei 7347/85, alterada pela Lei 8844/94, trouxe a possibilidade de danos a direitos difusos e coletivos, tanto patrimoniais como extrapatrimoniais. Não obstante a positivação, há autores que não admitem tal hipótese. Assim, o presente artigo tem o objetivo de compreender a moral ambiental em nível coletivo para propugnar a aceitação do dano moral ambiental, adotando como referencial teórico a obra do jurista e filósofo François Ost.

\section{BREVE REVISÃO TEÓRICA DA LEGISLAÇÃO PÁTRIA}

Iniciando a análise pela Lei Maior, ainda que cronologicamente posterior, observa-se que a mesma define o direito ao meio ambiente equilibrado no artigo 225. Para o estudo, destacou-se a importância do parágrafo $3^{\circ}$, o qual enuncia que "as condutas e atividades consideradas lesivas ao meio ambiente sujeitarão os infratores, pessoas físicas ou jurídicas, a sanções penais e administrativas, independentemente da obrigação de reparar os danos causados".

A responsabilidade civil pelos danos causados ao meio, por sua vez, foi regulamentada na Lei ${ }^{\circ}$ 6938/81, que trata da Política Nacional do Meio Ambiente, tendo sido recepcionada pela Magna Carta. O artigo 14, parágrafo $1^{\circ}$, determina a obrigação de reparar os danos ao meio e a terceiros, fixando uma responsabilidade 
objetiva ao infrator. A reparação deverá ser feita, prioritariamente, através da reconstituição do bem lesado ao seu status quo ante (reparação específica do dano ambiental) ou, quando assim não for possível, por meio de indenização pecuniária. Neste caso, se ferir direito difuso ou coletivo, o montante destina-se ao Fundo constante no artigo 13 da Lei $n^{\circ}$ 7347/85; caso for violado direito individual, será para o terceiro que sofreu a lesão. No entanto, esta lei não define (nem diferencia) qual tipo de dano engloba, fato que originou a celeuma a respeito do dano moral.

A Ação Civil Pública, regulada pela Lei $7347 / 85$, por sua vez, servia de instrumento para a defesa de diversos direitos, mas não abordava o aspecto extrapatrimonial dos mesmos. Com o intuito de torná-la mais consonante com a Constituição Federal de 1988, que em seu artigo $5^{\circ}$, incisos V e X, consagrou a autonomia do dano moral em relação ao patrimonial, veio a Lei 8844/94 alterar seu artigo $1^{\circ}$, determinando a reparabilidade do dano moral, independentemente de culpa. Restou consagrada a Teoria da Reparação Integral dos danos a direitos difusos e coletivos, entre eles o meio ambiente, como já defendia Leite (2000).

Inobstante a fundamentação legal ao dano extrapatrimonial, há teóricos, entre eles Stoco (2004), que não admitem tal hipótese. Nas palavras do autor (STOCO, 2004, p. 8):

Falar em "dano moral ambiental" é desvirtuar o objetivo da Magna Carta e tangenciar os princípios que informam a responsabilidade civil, pois o que se resguarda é o meio ambiente e não o dano causado à pessoa, individual ou coletivamente. Estes, caso sofram prejuízos, por danos pessoais (físicos) ou materiais (em seus bens), terão direito de ação para obter a reparação por direito próprio, mas não podem beneficiar-se do resultado alcançado pelo Ministério Público ou pelas entidades legitimadas a ingressar com ações civis públicas para a proteção ambiental, salvo quando a ação tenha natureza diversa, como a proteção do consumidor ou qualquer outro interesse difuso ou coletivo que cause dano de per si e possa ser individualizado e qualificado posteriormente.

Esta parcela da doutrina concentra-se, portanto, em dois argumentos: a) os direitos da personalidade seriam atributos exclusivos do ser humano, não podendo o meio ambiente sofrer um dano moral; b) somente o indivíduo, na sua subjetividade, poderia ter seus valores e sentimentos maculados, não existindo uma moral de grupo a violar. Na tentativa de desconstruir essas concepções, buscando uma base filosófica que possibilite a compreensão da moral ambiental em nível coletivo, passa-se ao estudo da obra de François Ost. 


\section{A VISÃo diALÉticA A RESPEITO DA RELAÇÃO HOMEM-MEIO}

AMBIENTE

Ost (1995) descreve o problema da crise ambiental como a crise dos vínculos e dos limites: o homem não sabe definir quais são os pontos de contato que possui com a natureza, aquilo que o a assemelha a ela, e também tem dificuldade em identificar qual é o elemento que o diferencia da mesma, que o torna ser humano. "Eis a crise ecológica: a desflorestação e destruição sistemática das espécies animais, sem dúvida; mas, antes de mais e sobretudo, a crise de nossa representação da natureza, a crise da nossa relação com a natureza" (OST, 1995, p. 8). O resultado dessa crise são duas noções diferentes sobre tal relação: a visão antropocêntrica, que estabelece a supremacia do homem sobre a natureza, e a visão ecológica radical, que afirma que a natureza é tudo, defendendo o panteísmo ecológico.

A primeira concepção da relação homem-natureza, vigente atualmente, foi produzida num contexto filosófico que pretendia negar todo conhecimento que fosse proveniente da religião, que tivesse cunho metafísico. Nesse contexto, Descartes, em O Discurso do Método, influenciado pela física de Isaac Newton, passa a preconizar a realização de uma reflexão filosófica baseada em um método matemático, partindo-se de premissas a serem analisadas separadamente para, então, chegar-se a uma conclusão. Como resultado dessa concepção metodológica, recria a concepção de mundo, explicando-o como um grande processo mecânico, constituído de matéria, dado mensurável e demonstrável.

No entanto, como mensurar o pensamento humano, as idéias? Para resolver tal questionamento, propõe a existência de duas realidades distintas, a matéria e o pensamento. Dessa maneira, opera-se a perfeita separação entre natureza e homem; aquela composta somente pela matéria, enquanto este, além da matéria, é composto também pelo pensamento. Erigi-se, a partir disso, a concepção dualista de mundo (CAPRA).

Essa construção epistemológica servirá de base para o desenvolvimento da ciência moderna, já que, por possuir a capacidade de pensar - "cogito, ergo sum" o homem teria supremacia sobre a natureza; é a partir dela que o homem torna-se "[...] a medida de todas as coisas, instala-se no centro do Universo, apropria-se dele e preparase para o transformar" (OST, 1995, p. 53). Capra (2006, p. 56) corrobora este pensamento: “A concepção cartesiana do universo como sistema mecânico forneceu 
uma sanção 'científica' para a manipulação e a exploração da natureza que se tornaram típicas da cultura ocidental”.

Pode-se observar o reflexo dessa noção no Direito no instituto da propriedade privativa - legitimada, segundo John Locke, pelo trabalho: “o Código Civil de 1804 iria traduzir esta inspiração sobre o terreno mais concreto do direito positivo, garantindo a absolutividade, a exclusividade e a perpetuidade dos direitos do proprietário" (OST, 1995, p. 62). Dessa forma, estabelecendo o gozo e a livre disposição dos bens ao proprietário, o Direito irá sedimentar a concepção de poder sobre a coisa, permitindo inclusive o seu perecimento.

Após séculos de completa hegemonia da concepção anterior, surge nos Estados Unidos, espalhando-se pela Noruega, Grã-Bretanha, Alemanha, Austrália, entre outros, um novo conceito a respeito da relação homem-natureza, que viria para se contrapor à vigente: a chamada "deep ecology". Essa nova corrente filosófica - que possui como obra de referência o livro Sand Country Almanac, de Aldo Leopold (1949) questionará pela primeira vez a visão cartesiana do mundo, propondo um retorno às origens, ao sagrado, para que o homem se reencontre com a natureza e reconheça-se como derivado dela. Dessa forma, “à relação científica e manipuladora da matéria, que é uma relação de distanciamento e de objetivação, substitui-se uma atitude fusora de osmose com a natureza - simultaneamente culto do corpo e canto poético, naturalização do corpo e humanização da natureza" (OST, 1995, p. 170).

Para uma melhor compreensão desta corrente filosófica, analisar-se-á seus principais princípios, enumerados de forma clara por Ost (1995). Primeiramente, ao defender o retorno à natureza como origem da vida, já que esta tudo compreende, conclui-se pela subjetivação da mesma, que passaria a ser tratada como sujeito de direito, com prerrogativas a opor aos seres humanos. Como conseqüência dessa idéia, passar-se-ia de uma visão antropocentrista para ecocentrista, em que o universo torna-se a referência; o homem perde, portanto, qualquer privilégio, já que é apenas uma pequena parcela daquele.

Desta redução de tudo à natureza resulta uma concepção holista, a qual se contrapõe ao individualismo vigente. Assim, partindo da igualdade de todos os seres e da interdependência de cada um para com os outros, confere-se prioridade ao todo. Nessa visão, todos os seres, incluindo os elementos abióticos, possuidores de valor intrínseco, formariam uma só comunidade moral, cada um com o mesmo direito em relação ao outro. 
Por fim, observa-se uma característica, oposta à concepção anterior: o monismo. Agora, ao invés da separação total entre homem e natureza, perdendo-se os vínculos, tem-se a total aproximação dos dois, esquecendo-se as distinções entre ambos. "Ali, tínhamos a dualidade sem qualquer ideia das relações e das identidades, com a hierarquia e a exploração em primazia; aqui, herdamos a unidade sem qualquer ideia das diferenças, com o confusionismo e o reducionismo em primazia” (OST, 1995, p. 180).

Conforme é possível observar, concordando com as críticas realizadas pelo autor a ambas as teorias, nenhuma delas constitui-se no fundamento idôneo para a construção de um regime jurídico que proteja adequadamente a natureza e sirva de base filosófica para a compreensão da moral ambiental (constituída por aspectos humanos e naturais). Enquanto a concepção dualista estabelece a supremacia do homem, que se considera dono e senhor da natureza - do que se conclui pela existência de uma moral constituída por aspectos apenas humanos -, a concepção monista preconiza a edificação da natureza como sujeito de direito, caso em que existiria uma moral natural, afastando-se elementos humanos.

Diante dessa crise paradigmática da relação homem-natureza, busca-se uma nova visão que aprenda a identificar os vínculos e os limites na proporção ideal, que conjugue os interesses do homem e da natureza sem supremacias; que seja, portanto, dialética. É somente através de tal concepção dialética que será possível vislumbrar a existência de uma moral ambiental, visto que esta é resultado da interdependência entre homem e meio ambiente, conforme se observa no fato de um dano ao meio ambiente causar efeitos reflexos ao homem. Dessa forma, nas palavras de Ost,

[...] depois do objecto e do sujeito, chega agora o tempo do projecto. As perspectivas ligadas sobre o sujeito e o objecto não têm, definitivamente, futuro. (...) O projeto, em contrapartida, não rejeita nem o sujeito nem o objecto. Pelo contrário, pressupõem-nos. Mas, longe de os absolutizar, põe-nos em relação. (...) A este rede de relações chamamos 'meio'. (OST, 1995, p. 273).

Buscando uma concepção dialética a respeito da relação homem-natureza, que saiba reconhecer os contrários como complementares e não como opostos que se excluem, Ost (1995) defende a adoção de uma epistemologia da complexidade ${ }^{1}$. Conforme o autor $(1995$, p. 280), complexo é “[...] todo o fenómeno que põe em jogo

\footnotetext{
${ }^{1}$ Apesar do uso da nomenclatura "epistemologia da complexidade" (OST, 2005, p. 280) e da referência a autores que tratam do assunto (P. LIVET, "Um facteur de complexité: le jeu de l'indétermination dans les relations humaines", in Les Théories de la complexité. Autour de l'oeuvre de Henri Atlan, Le Seuil, 1991, p. 436), trata-se muito mais de uma visão dialética (que embasa toda sua obra) que propriamente complexa, conforme se observa na seguinte passagem: "Esta epistemologia da complexidade assenta, quanto a ela, num pensamento dialéctico, de que importa sublinhar a originalidade. Na sua base, encontramos a ideia de que os elementos distintos e mesmo antagónicos têm contudo, necessariamente, uma 'parte ligada'" (OST, 2005, p. 282). Para saber mais sobre o dano moral ambiental a partir da Teoria da Complexidade vide: ZANELLA et all. Reparação extrapatrimonial dos danos ambientais à luz da Teoria da Complexidade de Edgar Morin. Revista Eletrônica do Curso de Direito da UFSM. Vol. 1, N. 2. 2006. P. 65-81. Para um estudo perfunctório sobre dialética, vide: KONDER, Leandro. O que é dialética. 27 ed. São Paulo: Brasiliense, 1994.
} 
uma diferença de níveis e uma circularidade entre estes diferentes níveis”, considerando como níveis distintos o homem e a natureza, os quais se condicionam mutuamente e interagem entre si. Dessa forma, cada elemento teria a capacidade de agir sobre o outro, sendo ambos causa e efeito, do que se conclui a interdependência entre homem e natureza, jamais a supremacia de um deles.

Por fim, como é intrínseco a toda a relação dialética, há sempre uma síntese, um "terceiro" que se extrai da relação original. No contexto da relação homem-natureza, seguindo os ensinamentos de Ost, a síntese ideal seria o "meio", esclarecendo que este é diferente de ambiente, que pressupõe o homem como centro e a natureza como cenário. A noção de meio é adequada porque é multifacetada, pode ser considerada sob o aspecto cultural e natural; ambígua, é o híbrido entre homem e natureza.

Segundo Ost (1995, p. 301), “de todas as manifestações naturais, a paisagem é, sem dúvida, uma das melhores ilustrações do 'meio'[...]", isto porque ela transparece aquilo que a natureza criou juntamente com as transformações operadas pelo homem, sendo estas realizadas conforme suas crenças, tradições e valores. Ost (1995, p. 302) corrobora esta idéia ao escrever que "[...] o meio é uma 'realidade construída, histórica e geograficamente, por um processo de combinação da natureza e da cultura [...]”.

É possível compreender, assim, a existência de uma moral ambiental que abarque homem e meio ambiente como seus elementos, formada por aspectos de ambos, absolutamente dialética. Dessa forma, não se está tratando de uma moralidade afastada do ser humano; também não se vê o homem como ser supremo e único, negando total autonomia de existência ao meio ambiente. Busca-se, então, através do reconhecimento dos vínculos e limites de ambos, reconhecer a interdependência existente nessa relação para, a partir disso, vislumbrar essa construção filosófica capaz de embasar a moral ambiental - a noção dialética de meio - e compreender, portanto, o dano extrapatrimonial ambiental.

Há, no entanto, a segunda objeção apresentada por Stoco (2004), que afirma a inexistência de uma moral pertencente a um grupo, em seu aspecto coletivo. $\mathrm{Na}$ tentativa de afastar esse argumento, procede-se agora ao estudo do tempo social, com base em Ost (2005).

\section{A CONSIDERAÇÃO DO TEMPO SOCIAL COMO CONSTRUTOR DA IDENTIDADE DOS POVOS}


Ost orienta seu pensamento partindo de duas teses que, quando se relacionam, culminam em uma terceira, a concepção ideal a respeito da relação direito-tempo. A primeira tese compreende o tempo como uma instituição social, ou seja, o poder do tempo na construção social, sedimentando concepções, valores, culturas. A segunda tese afirma que a principal função do Direito é a instituição da sociedade: "o direito é um discurso performativo, um tecido de ficções operatórias que redizem o sentido e o valor da vida em sociedade" (OST, 2005, p. 13).

A terceira tese trata justamente da interdependência, do mútuo condicionamento entre tempo e direito: a força de uma lei está relacionada com seu tempo de vigência; na prescrição e decadência, o tempo faz os efeitos jurídicos perderem eficácia. Tal concepção também conduz à compreensão do tempo como fator de integração da sociedade, coordenando os ritmos individuais para que convirjam a um mesmo objetivo comum. A partir dessa idéia, nega-se qualquer visão determinista do futuro; ao mesmo tempo, frente às concepções individualistas das sociedades contemporâneas, buscam-se mecanismos capazes de unir os grupos sociais para que caminhem em um só passo.

Mas, afinal, de que tempo se está tratando? Visto que possui capacidade instituinte, o tempo trabalhado pelo autor é o social: “(...) é o tempo 'sócio-histórico', terceiro tempo radicalmente cultural, produto das construções coletivas da história” (p. 23). Em tal concepção, o "tempo público (...) procede antes de tudo de representações mentais e de projeções de valor - ele é o fruto de uma construção deliberada, o que denominamos "temporalização"' (p.21). Esse aspecto cultural do tempo torna-se claro quando se observa a existência de diversas formas de contar o tempo (calendários), conforme a história de cada povo, cada qual com um momento fundador distinto.

Para que esse entendimento vigore, Ost abandona a divisão linear do tempo em passado-presente-futuro e o estabelece, dinamicamente, em quatro passos: do lado do passado, a memória e o perdão; do lado do futuro, a promessa e o questionamento. Para compreender a existência de um substrato que una a sociedade e, assim, a existência de uma moral ambiental coletiva, destaca-se ao presente estudo os tempos "memória" e "promessa". No entanto, é necessário considerar que, para que haja uma "temporalização" bem sucedida, nenhum desses tempos pode ser tratado isoladamente; estão todos interligados, nenhum deles é suficiente. Da mesma forma, nenhum deles é absoluto em si mesmo: “(...) há muito de esquecimento na memória e muito de memória no perdão..." (OST, 2005, p. 18). A tensão entre estabilidade e mudança permeia os mesmos constantemente. 


\subsection{Memória}

O direito e a memória estão intimamente ligados: o direito institui aquilo que a memória guarda - o momento fundador, os valores sociais, a identidade coletiva. Falase aqui, novamente, de uma memória social e objetiva, capaz de forjar e manter o laço social, ligando as gerações.

Nessa esteira, a memória não é uma compilação de fatos do passado, mas, paradoxalmente, é uma (re)construção coletiva, é seletiva e, portanto, ativa. É justamente no ato de lembrar e reinterpretar que ela permanece viva. É através desse processo de regeneração que se estabelece o passado digno de memória. É com base nesta que “(...) erige-se a consciência coletiva, na falta da qual não haveria, pura e simplesmente, qualquer ação social possível, nem no presente, nem, a fortiori, no futuro" (OST, 2005, p. 50).

Através dessa construção dinâmica e ativa realizada pela memória, estabelece-se o "momento fundador" da sociedade - aquele que, simbolicamente, legitima o poder instituído - ocorrendo a sedimentação do laço social, já que há a união dos indivíduos em torno de uma origem comum, existente nesse passado coletivo. Constitui-se, assim, em relação a um grande número de indivíduos, a essência do que se costuma chamar nação: ter uma história em comum e, dessa forma, considerar-se um grupo.

Como salientado anteriormente, o direito e a memória possuem íntima relação no desempenho de suas funções. Por isso, torna-se imprescindível observar a atuação do direito como "guardião da memória social" (OST, 2005, p. 84).

O principal papel do direito, em detrimento da visão positivista que evoca a função de regular condutas e dirimir conflitos, é o de instituir uma sociedade. Ele determina o idioma oficial, o que constitui forte laço social, apontado como um dos elementos constituintes da nação ${ }^{2}$. A língua nacional é importante porque é o instrumento que operacionaliza a construção da cultura, sua manutenção e transmissão através das gerações. Não é a capacidade de transmitir valores, costumes, tradições, conhecimento um dos fatores que diferencia o ser humano dos outros animais? Nas palavras de Ost (2005, p. 86), a "língua não é apenas um código de comunicação, mas a

\footnotetext{
${ }^{2}$ Dallari (2006) parte da diferenciação entre sociedade e comunidade. Aquela é o grupo humano que possui convivência comum em a specto jurídico e político, formada a partir de atos de vontade, não se exigindo qualquer semelhança de sentimentos. A comunidade (ou nação) existe como fato de forma anterior a qualquer ato jurídico que determine um poder supremo a orientá-la. Nas palavras do autor (DALLARI, 2006, p. 134), “... conscientes desse fato, tais pessoas passam a agir de maneira a fortalecer cada vez mais a união, podendo haver, neste momento, a partici pação da vontade, mas só depois que a comunidade já existe. A circunstância de pertencerem à mesma comunidade faz com que os seus membros tenham sentimentos comuns, experimentem estados psicológicos também comuns e, como conseqüência última, desenvolvam costumes comuns".
} 
própria expressão da cultura, (...) uma linguagem comum é uma maneira importante de preservar o patrimônio de uma nação".

Neste contexto insere-se o papel da tradição, também importante para a formação e manutenção do laço social. A tradição é constituída de dois aspectos: a continuidade e a conformidade. Conforme Ost (2005, p. 61), "a tradição é uma anterioridade que cria autoridade; ela é um código de sentido e de valores transmitidos de geração a geração...”. É certo que, sob um prisma dinâmico, a tradição há de ser revista, reinterpretada e adaptada, sob pena de se tornar obsoleta diante das mudanças sociais. No entanto, sua manutenção é indispensável, pois possui "grande utilidade no plano normativo, desde quando transmite o relato das origens (...), a identidade normativa, sem a qual povos e indivíduos nem teriam consciência de si mesmos (OST, 2005, p. 63)”. Por fim, inscreve os indivíduos e os povos em uma continuidade temporal, o que confere sentido à vida em comum, salientando a posição de herdeiro que cada um ocupa na história social.

No exercício de sua função constitutiva-memorizante, o direito estabelece papéis e estatutos (estados da pessoa) os quais, ainda que dinâmicos, conferem estabilidade às relações e expectativas sociais, garantindo a segurança jurídica, o que aperta o nó do laço social: cada um sabe o papel que lhe cabe na sociedade, podendo buscar sua modificação se assim lhe aprouver. De forma dialética, através de tais estatutos, o direito traz estabilidade à mudança social operada pelo livre-arbítrio individual: “... ele atribui a personalidade moral a um agrupamento...” (OST, 2005, p. 88).

Por fim, com a capacidade de sedimentar tal personalidade moral do grupo elemento essencial para a aceitação do dano extrapatrimonial ambiental -, nas palavras de Ost (2005, p. 89), “a contribuição mais essencial do direito à fixação de uma memória social e à manutenção de uma tradição nacional reside certamente na afirmação (...) dos valores fundamentais da coletividade. É na Constituição que, de modo positivo, e no Código Penal, de modo negativo, esses valores são afirmados com a maior clareza".

Diante do exposto, inobstante o declínio da memória nas sociedades contemporâneas, ocasionado principalmente pela abundância de informação pontual e imediata em detrimento de uma coerência temporal, e pela fragmentação da sociedade em subgrupos de interesses, é compreensível a importância da memória para a existência da consciência coletiva no presente. É o tempo da memória (dialética) que é capaz de criar uma sociedade e conferir-lhe sentido; não há sociedade sem memória! 
No entanto, é necessário analisar também a relevância do tempo "promessa" para que se assegure a manutenção do laço social; agora, especialmente em direção ao tempo futuro.

\subsection{Promessa}

O tempo da promessa é tanto quanto ou até mais importante que a memória para a formação da consciência coletiva. Ele trabalha, no entanto, prospectivamente, estabelecendo o laço social no momento presente para assegurar um futuro com sentido comum. O problema ambiental, mais do que qualquer outro, só poderá ser abordado da forma adequada se analisado através dessa perspectiva. É justamente por isso que Ost (2005, p. 188) traz esse tema no prólogo do tempo da promessa, observando-o sob essa perspectiva: "elaborava-se um novo conceito de responsabilidade, decididamente voltado para o futuro: não mais a responsabilidade-imputação (sanção de uma falta passada), mas a responsabilidade no sentido de missão assumida coletivamente para o futuro".

Conforme já se depreendeu da filosofia de Ost (2005), também esse tempo é dialético em si mesmo, pois, simultaneamente, vincula as partes ao compromisso assumido e confere-lhes liberdade em acordar o que desejam - os pactuantes são sujeitos. Neste contexto, chama-se de "metamórfico" este tempo que estabelece equilíbrio entre estabilidade (o compromisso) e mudança (a liberdade em pactuar) na figura da promessa-instituição.

A promessa como modalidade normativa - seja na forma da Constituição (a promessa por excelência), da lei, tratado internacional ou contrato particular - repousa sobre uma socialidade prévia: “(...) é apenas sobre o fundo desta confiança partilhada que ela pode tornar-se laço social” (OST, 2005, p. 194). É neste âmbito que se situam diversos princípios que regem as relações jurídicas, os quais buscam estabelecer tal base de confiança, podendo-se citar o princípio da segurança jurídica e da probidade e boa-fé como exemplos.

Nessa esteira, a promessa é importante ao corpo social porque tem a essência de investimento; investe-se no futuro através do autocomprometimento. Ela tem a capacidade de criar responsabilidade consciente porque não é heterônoma, mas é da ordem da autonomia e da emancipação. Por certo, não se trata de adotar uma perspectiva hobbesiana para esse compromisso - baseado no medo, gerando dominação - nem ampliar ilimitadamente o poder de ação individual (ARENDT, 1988 apud OST, 
2005), mas sim de optar por uma visão que equilibre ambos e possa estabelecer uma promessa plausível. Assim, "a promessa é, sobretudo, uma figura dialética de mediação, que permite ao sujeito subsumir suas intenções voluntárias sob princípios éticos prévios..." (OST, 2005, p. 203).

A promessa que engendra um sentido comum ao grupo social, além da confiança entre os cidadãos, exige a confiança destes nos governantes, que devem atuar visionando as expectativas sociais. Assim, faz-se indispensável a prática de uma democracia verdadeiramente representativa por meio de um grupo de parlamentares que seja reflexo da vontade soberana do povo. Conforme Burdeau (1980, p. 228-229 apud OST, 2005, p. 246), é necessário que a elaboração de uma lei, para os cidadãos “(...) signifique a seus olhos um comprometimento tomado em nome deles; é preciso que eles associem as manifestações exteriores do poder à idéia de um projeto coletivo que o grupo formula para dominar seu destino". Em suma, é mister que os indivíduos pensem e ajam politicamente como sujeitos históricos.

Diante disso, não há nada mais importante que a Constituição, a carta que orienta o grupo num sentido comum, é a base para a elaboração de novas normas e carrega os valores fundamentais da nação - “... valores e princípios simultaneamente enraizados numa memória e portadores de um projeto futuro" (OST, 2005, p. 230). Assim, "receptáculo de todas as promessas que o corpo social pode fazer a si próprio, a Constituição é, por excelência, o instrumento jurídico de ligação com o futuro" (OST, 2005, p. 252).

Assim, estando compreendida a noção dialética de tempo social e observada a importância dos tempos da memória e da promessa para a sedimentação do laço social, para a formação de uma base jurídica coerente com os valores sociais e para a construção de um futuro comum ao grupo, torna-se viável a hipótese do dano moral ambiental em nível coletivo. Adotando essa perspectiva que considera o papel instituidor do tempo (e do direito), resulta aceitável a existência de uma personalidade moral de grupo, distanciando-se a crítica doutrinária que não admite essa realidade.

\section{CONSIDERAÇÕES FINAIS}

Com base no estudo da obra de François Ost (2005), visualizando uma relação dialética entre homem e meio ambiente, foi possível conceber a existência da moral ambiental, não fora do ser humano, mas a partir da interdependência de ambos, que é representada pelo "meio". A moral coletiva, por sua vez, é compreendida considerando- 
se o tempo da memória e o tempo da promessa, instituidores e integradores - o primeiro, em relação ao passado; o segundo, em relação ao futuro - a qual confere sentido à vida em comum - sentimentos, valores, crenças, hábitos partilhados pelo grupo que são passados de geração a geração, infinitamente.

Nesse contexto, a Lei $\mathrm{n}^{\mathrm{o}} 7.347 / 85$ (alterada pela Lei $\mathrm{n}^{\mathrm{o}}$ 8.844/94), que prescreve a responsabilidade por danos morais causados quando da ocorrência de um desastre ambiental, foi interpretada de forma sistemática com a Constituição Federal e à luz da Teoria da Proteção Integral do meio ambiente. Da conexão entre os referenciais teóricos e a referida interpretação, conclui-se pela viabilidade da tese do dano moral ambiental no ordenamento jurídico brasileiro.

Propugna-se, portanto, pela ampla aceitação do dano extrapatrimonial ambiental pela doutrina e jurisprudência. Estes, se cientes da imperiosidade da proteção ambiental, considerando a realidade do planeta e as perspectivas negativas que se apresentam a todos, constatarão a necessidade de adoção de um paradigma que renove a representação que o homem possui de sua relação com a natureza, conduzindo, enfim, à compreensão da importância do dano extrapatrimonial ambiental.

\section{REFERÊNCIAS BIBLIOGRÁFICAS}

CAPRA, Fritjof. O ponto de mutação. São Paulo: Cultrix, 2006.

DALLARI, Dalmo de Abreu. Elementos de Teoria Geral do Estado. São Paulo: Saraiva, 2005.

KONDER, Leandro. O que é dialética. 27 ed. São Paulo: Brasiliense, 1994.

LEITE, José Rubens Morato. Dano ambiental: do individual ao coletivo extrapatrimonial. São Paulo: RT, 2000.

OST, François. A natureza à margem da lei: a ecologia à prova do direito. Lisboa: Instituto

Piaget, 1995.

OST, François. O tempo do direito. Bauru: EDUSC, 2005.

STOCO, Rui. Tratado de Responsabilidade Civil. 6ª ed. São Paulo: RT, 2004.

ZANELLA et all. Reparação extrapatrimonial dos danos ambientais à luz da Teoria da Complexidade de Edgar Morin. Revista Eletrônica do Curso de Direito da UFSM.

Vol. 1, N. 2. 2006. P. 65-81. 